\title{
The Indoor Climate Library and its Application to Heat and Moisture Transfer in a Vehicle Cabin
}

\author{
Victor Norrefeldt ${ }^{1}$, Daniel Andersson ${ }^{2}$, Arnav Pathak ${ }^{1}$, Hubertus Tummescheit ${ }^{2}$ \\ 1: Fraunhofer-Institute for Building Physics \\ Fraunhoferstr. 10, D-83626 Valley, Germany \\ 2: Modelon AB \\ Ideon Science Park, Beta 6 building, Scheelevägen 17, S-22370 Lund, Sweden \\ victor.norrefeldt@ibp.fraunhofer.de, daniel.andersson@modelon.com, \\ arnav.pathak@ibp.fraunhofer.de, hubertus.tummescheit@modelon.com
}

\begin{abstract}
This paper presents the newly developed Indoor Climate Library. The library facilitates simulation of the coupled heat and moisture transfer through envelopes and the interaction of envelopes with the interior air. The computation of coupled heat and moisture transfer becomes more and more important for the development of electric vehicles. Due to the lack of waste heat from the combustion engine the heating of a vehicle cabin during winter time becomes a challenge. One way to reduce heat losses through the envelope is to add insulation. However, insulation bears the risk of water accumulation and its performance usually decreases with increased water content. The Indoor Climate Library helps the user to detect such problems early in the product development process and to find remedies.
\end{abstract}

Keywords: Heat and moisture transfer; Indoor air, Modelica Library

\section{Introduction}

To compute heat and moisture flow through building wall constructions, Nouidui [1] has built the Building Physics Library as research code. The authors have now rearranged and updated this code with the focus on user friendliness and increased applicability. Templates have been added allowing the quick setup of a model. Furthermore, the package structure has been rearranged to allow the user to easily navigate the library.

In Modelica different libraries are provided for the computation of building related problems. The
Buildings Library [2-5] contains thermal models for walls, windows, shading systems, HVAC components, controls, etc. Even components from the Modelica Standard library allow quick setup of thermal models of wall constructions. However, these libraries are limited to the thermal aspect of energy flows but neglect the moisture flow through constructions. Raised moisture levels adversely affect material properties. Risk of mold growth increases resulting in a harmful indoor environment [6]. Thermal conductivity of insulation materials usually increases with moisture content resulting in a degradation of insulating properties. Furthermore, the moisture transfer itself leads to a considerable enthalpy flow when evaporation or condensation occur, affecting wall temperatures considerably. The goal of the Indoor Climate Library is to provide a tool that predicts heat and moisture flows. Based on outside weather conditions the temperature and humidity profile in the enclosure layers and of the inner air are computed. The classical application field of the library is for buildings. However, recent developments of energy efficient heating systems for electrical vehicles show the need of using more insulation materials. Therefore, the library focuses on applications in the automotive and aviation sector as well.

\section{Use of the Indoor Climate Library}

The following section describes how to use the Indoor Climate Library. 


\begin{tabular}{|llll||}
\hline \multicolumn{2}{ll}{ Nomenclature } & $w$ & Water content $\left[\mathrm{kg} / \mathrm{m}^{3}\right]$ \\
$A$ & Area $\left[\mathrm{m}^{2}\right]$ & $w_{f}$ & Free water saturation $\left[\mathrm{kg} / \mathrm{m}^{3}\right]$ \\
$A_{w}$ & Absorption coefficient $\left[\mathrm{kg} /\left(\mathrm{m}^{2} \cdot \mathrm{h}^{0.5}\right)\right]$ & $w_{\max }$ & Maximum water content $\left[\mathrm{kg} / \mathrm{m}^{3}\right]$ \\
$c$ & Specific heat capacity of dry material $[\mathrm{J} / \mathrm{kg} \cdot \mathrm{K}]$ & $\beta_{c}$ & Convective mass transfer coefficient \\
$c_{w}$ & Specific heat capacity of water $[\mathrm{J} / \mathrm{kg} \cdot \mathrm{K}]$ & & {$\left[\mathrm{kg} /\left(\mathrm{m}^{2} \cdot\right.\right.$ Pa $\left.)\right]$} \\
$d$ & Thickness $[\mathrm{m}]$ & $\delta$ & Water vapor permeability $\left[\mathrm{m}^{2} \cdot \mathrm{s}\right]$ \\
$D_{w}$ & Liquid transport coefficient $\left[\mathrm{m}^{2} / \mathrm{s}\right]$ & $\varepsilon$ & Emissivity $[-]$ \\
$D_{w r}$ & Liquid transport coefficient at redistribution $\left[\mathrm{m}^{2} / \mathrm{s}\right]$ & $\lambda$ & Thermal conductivity $[\mathrm{W} / \mathrm{m} \cdot \mathrm{K}]$ \\
$D_{w s}$ & Liquid transport coefficient at suction $\left[\mathrm{m}^{2} / \mathrm{s}\right]$ & $\mu$ & Water vapor diffusion number $[-]$ \\
$f$ & Form factor $[-]$ & $\rho$ & Density $\left[\mathrm{kg} / \mathrm{m}^{3}\right]$ \\
$H$ & Enthalpy $[\mathrm{J} / \mathrm{kg}]$ & $\sigma$ & Planck constant $5.67 \cdot 10^{-8}\left[\mathrm{~W} /\left(\mathrm{m}^{2} \cdot \mathrm{K}^{4}\right)\right]$ \\
$h_{c}$ & Convective heat transfer coefficient $\left[\mathrm{W} / \mathrm{m}^{2} \cdot \mathrm{K}\right]$ & \multicolumn{2}{l}{} \\
$\dot{\mathrm{m}}$ & Mass flow rate $\left[\mathrm{kg} /\left(\mathrm{m}^{2} \cdot \mathrm{s}\right)\right]$ & $\mathrm{Subscripts}$ \\
$p_{\text {water }}$ & Water vapour pressure $[\mathrm{Pa}]$ & $i, j$ & numeration indexes \\
$\dot{q}$ & Heat flow rate $\left[\mathrm{W} / \mathrm{m}^{2}\right]$ & $l$ & liquid \\
$T$ & Temperature $[\mathrm{K}]$ & $v$ & vapor \\
\hline
\end{tabular}

\section{$2.1 \quad$ Before modeling}

Before modeling the user needs to answer the following questions:

- How many domains are needed

- How many walls are needed

- What materials are used

- How many windows are needed

- What window types are used

- To which domains do these walls and windows connect

- How many outside surfaces are needed

- How are the surfaces oriented

- Time and place

- Which weather data to use

When having found an answer to these questions, the user can build the whole model from predefined parameterized templates: The wall and window templates allow quick creation of models of different enclosures. The domain model contains a model of the air in a room that is connected to the walls and windows. Outside surfaces are the interface between wall templates and the environment. The environment provides the boundary conditions of the simulation.

\subsection{Wall Template}

The wall template consists of ten material layers. The default model for a material layer is the "None"- model. This is a passive model that can be exchanged by the needed material layer models. To configure the wall model, the user selects the needed material from a drop-down list.

Figure 1 shows the parameter dialog of a material layer. The number of nodes, the layer thickness, the discretization scheme and initial conditions must be set. The default discretization scheme uses small nodes near material layer boundaries and larger nodes in the middle. By changing the status of a radio button the user can choose to define a custom discretization. Another radio button allows the user selecting to enter the initial water content or the initial relative humidity of the material. Furthermore, the initial temperature can be set.

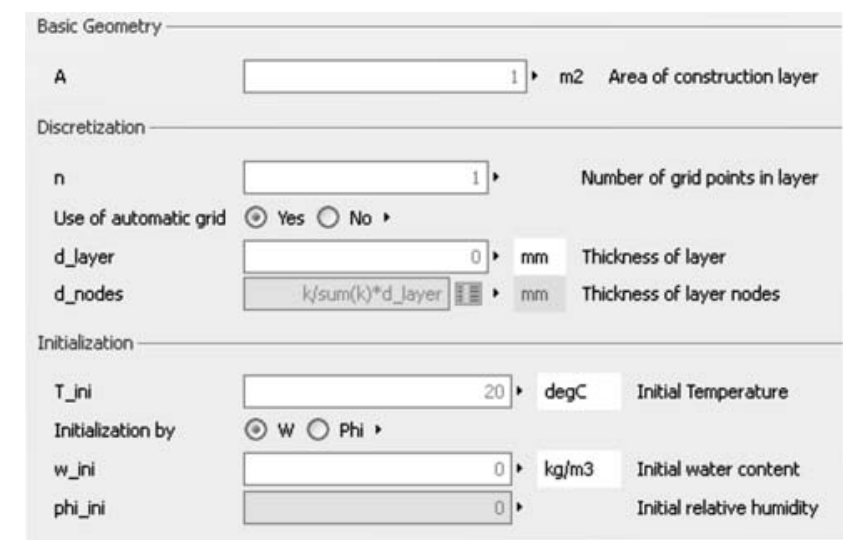

Figure 1: Parameterization of the material layer model 


\subsection{Window Template}

The type of window is selected from a drop-down list. Models for one, two and three-pane windows are available. Heat transfer through conduction, convection, long-wave radiation, transmission and absorption of solar radiation are taken into account when computing pane temperatures. The transmitted solar radiation is propagated to the adjacent domain.

\subsection{Domain template}

A rectangular room is a simple example for a domain. It consists of an air volume and of and six inside surfaces. The surface is considered as the infinitesimally narrow layer between the air volume and the wall. The wall side of the surface transports heat and moisture by conduction. The air side of the surface exchanges heat and moisture convectively with the adjacent air volume. A radiation node estimates the radiation between surfaces. View factors in the radiation node are computed from the connected surface's relative absorption weighted areas. For building applications this approach is sufficiently accurate [4]. If the user possesses more advanced view factors, a more detailed radiation model taking the real view factors into account, can be used. Windows are treated like any other wall in the domain model except that a further connection to a radiative source node is needed for transmitted solar radiation.

Figure 2 shows the parameterization of a domain model. The user gives the number of surfaces, their area, convective heat and moisture transfer coefficients or correlations and long-wave emissivities. If radiative or convective heat sources are contained in the domain their number must be given and corresponding models connected with the domain. For the air volume, the volume and initial pressure, temperature and relative humidity must be entered.

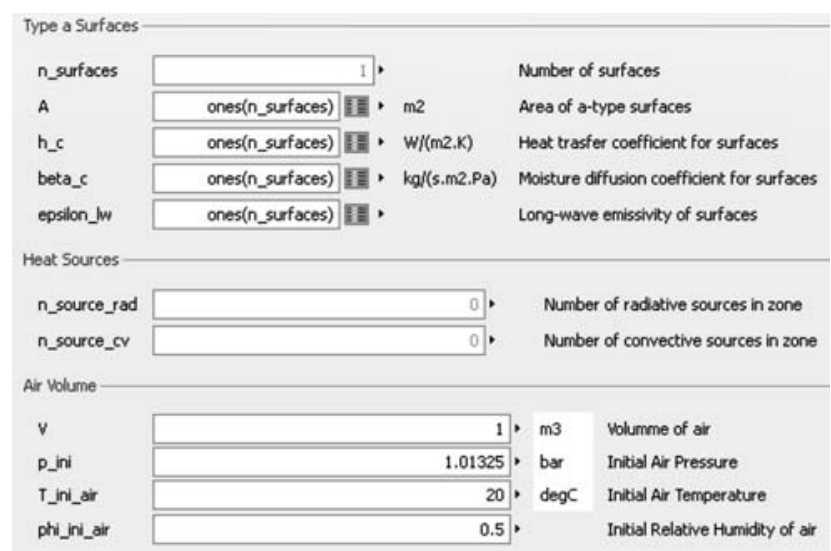

Figure 2: Parameterization of the domain model

\subsection{Outside Surfaces}

The geometric parameters of an outside surface are area, slope and azimuth angle (Figure 3). The surface model has an outer instance of the environment model.

As for the inside surface, heat and moisture is transported by conduction on the wall side and by convection on the air side. Radiation and radiation parameters are split into long-wave and short-wave radiation. Long wave radiation is exchanged with surrounding earth and with the sky. Short wave radiation is provided by the sun. A distinction is made between direct and diffuse solar radiation. A geometrical model computes the impact angle of the sun to determine the direct solar radiation. This angle depends on the slope and azimuth of the surface, location and time. Diffuse radiation is independent of the surface orientation, e.g. light also enters through a north facing window during daytime.

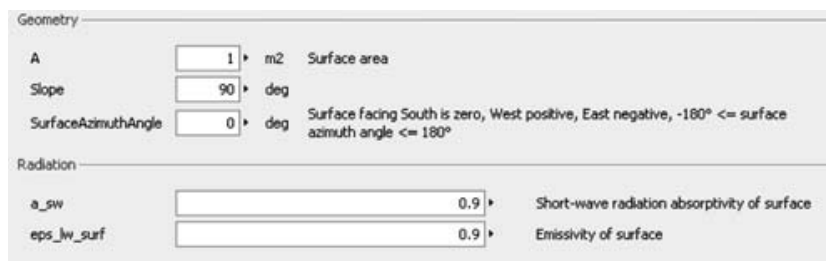

Figure 3: Parameterization of the outer surface model

\subsection{Environment model}

The environment model is used at the top-level of simulation models as an inner component. Information comes from weather files of test reference year data and is used in all models referring to outside weather conditions. The outputs from the component are the air temperature, humidity and pressure, wind speed and direction, intensity of direct and diffuse solar radiation, intensity of terrestrial and sky radiation and cloudiness.

The user selects a weather data file and the location of the building or cabin. This location is important for the geometrical sun model. Depending on the time format of the weather data file, a correction of the local standard time longitude needs to be entered. For GMT this correction is zero, for CET $-15^{\circ}$. To assess the reflection of solar and sky radiation by the soil, the corresponding parameters need to be entered. Meaningful standard values are set as default. The user needs to provide the start time and date of the simulation and the start time and date of weather data. This is necessary to align the weather data, the sun position and the simulation time in the integrator. 


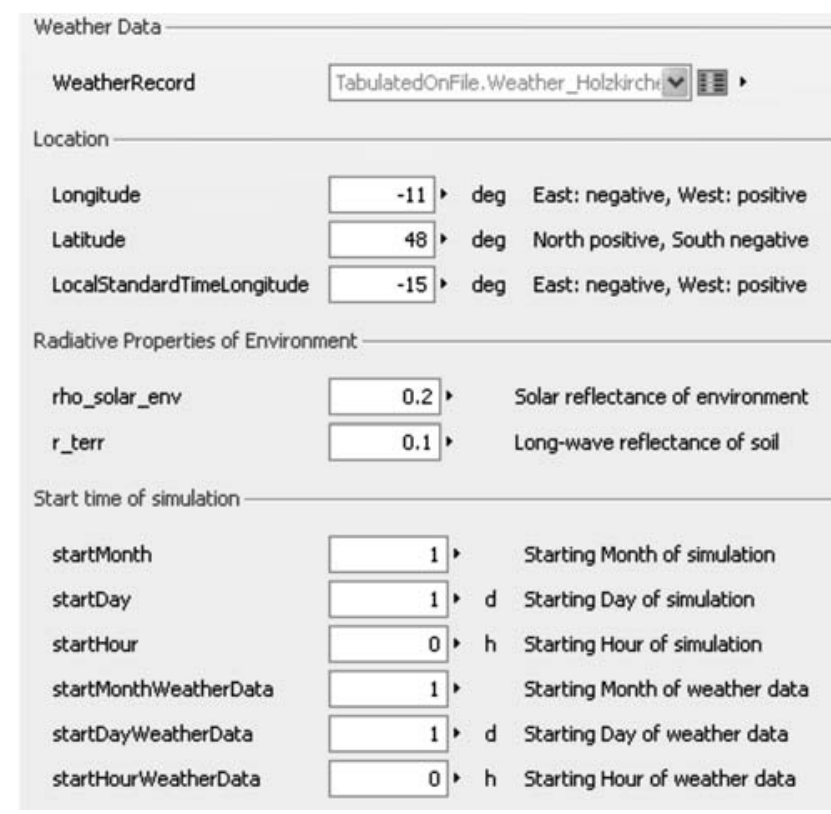

Figure 4: Parameterization of the environment model

\section{Technical background of the In- door Climate Library}

In this section, the principles of hygrothermal simulation are described.

\subsection{Water storage function}

The water storage function describes the relation between water content and relative humidity of a material. This function is usually non-linear and often increases more steeply at higher relative humidity. It needs to be determined experimentally. At $100 \%$ relative humidity free water saturation $w_{f}$ is reached. An example of water storage functions is shown in Figure 5.

The porosity of a material indicates the maximal water content $w_{\max }$. When all pores are filled with liquid water the material cannot be further penetrated by water. This maximal water content is above the free water saturation provided by the moisture storage function. In the range between the free water saturation and maximal water content the relative humidity remains equal to one, and is therefore independent of the water content. Up to the free water saturation, the material can be in an equilibrium state. Above no boundary condition exist that could maintain the reached water content [8].

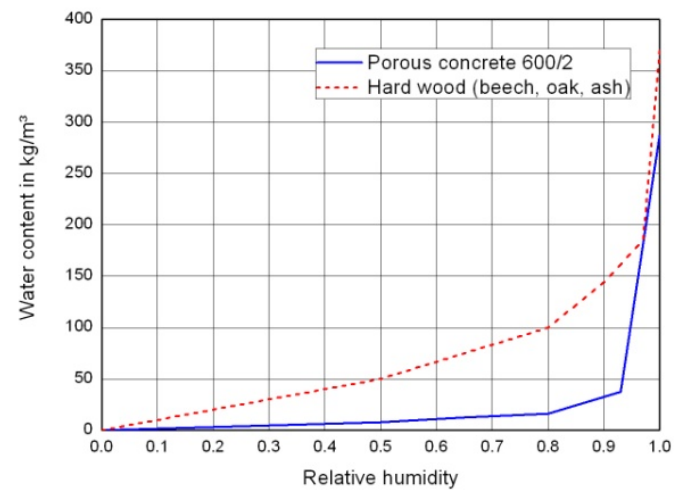

Figure 5: Examples of water storage functions [7]

\subsection{Heat flow}

The heat flow through a material node is obtained from the difference of the temperature $T$ between nodes $\mathrm{i}$ and $\mathrm{i}+1$, the conductivity $\lambda_{i}$ and the length $d_{i}$ of node $\mathrm{i}$ :

$$
\dot{q}_{i}=\lambda_{i} \cdot \frac{T_{i}-T_{i+1}}{d_{i}}
$$

For some materials thermal conductivity is constant, e.g. concrete: $\lambda=0.24 \mathrm{~W} /(\mathrm{m} \cdot \mathrm{K})$. Other materials like mineral wool show an increase of thermal conductivity at higher water contents (Figure 6). The Indoor Climate Library uses a replaceable thermal conductivity model to match the type of material.

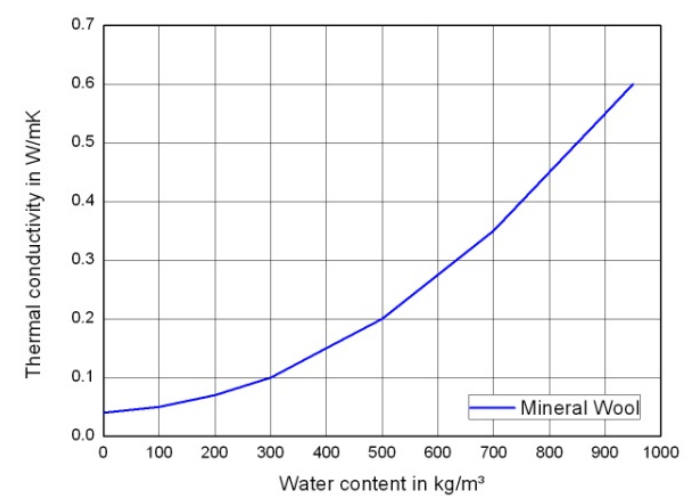

Figure 6: Example for increase of thermal conductivity with water content [7]

\subsection{Water vapor diffusion}

The driving potential for water vapor diffusion is the difference of the water vapor pressure $p_{\text {water }}$ between nodes $i$ and $i+1$.

$\dot{m}_{v, i}=\delta_{i} \cdot \frac{p_{w a t e r, i}-p_{w a t e r, i+1}}{d_{i}}$ 
The permeability $\delta_{i}$ of a material to water vapor is obtained from a function depending on the material node's temperature $T_{i}$ and the water vapor diffusion number $\mu_{i}$ (equation (3)). This number is a property of the material; for stagnating air it is by definition one. Depending on the type of material it can be constant (e.g. porous concrete $600 / 2: \mu=6.7$ ) or vary with relative humidity (Figure 7).

$\delta_{i}=\frac{2 \cdot 10^{-7} \cdot T_{i}^{0,81}}{101300 \cdot \mu_{i}}$

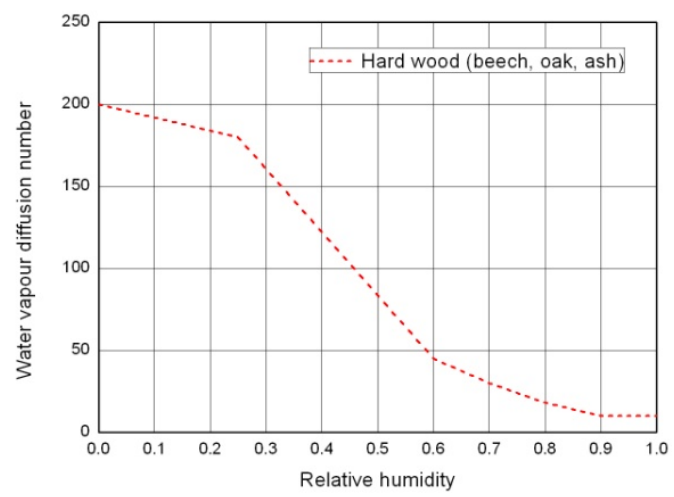

Figure 7: Example of relative humidity dependent water vapor diffusion coefficient [7]

\subsection{Liquid water transport}

Some materials are able to transport liquid water by capillary suction. Liquid transport is driven by the difference of water content $w_{i}$ between material node $\mathrm{i}$ and $\mathrm{i}+1$.

$\dot{m}_{l, i}=D_{w, i} \frac{w_{i}-w_{i+1}}{d_{i}}$

The liquid transport coefficient $D_{w}$ depends on whether the material surface is wet due to rain or whether it is dry. On a wet surface suction occurs, if the surface is dry redistribution occurs. The redistribution factor $D_{w r}$ can be estimated by a factor of 10 smaller than the suction factor $D_{w s}$ [9].

Often, the water absorption coefficient $A_{w}$ is given. For example, porous concrete has a $A_{w}$ coefficient of $5.4 \mathrm{~kg} /\left(\mathrm{m}^{2} \cdot \mathrm{h}^{0.5}\right)$. Künzel [8] suggests equation (5) to compute the liquid transport coefficient at suction from $A_{w}$, the free water saturation and the actual water content:

$D_{w s, i}=3.8 \cdot\left(\frac{A_{w}}{w_{f}}\right)^{2} \cdot 1000^{\left(\frac{w_{i}}{w_{f}}-1\right)}$

\subsection{Heat and Moisture Balance for a material layer node}

The sum of entering and leaving heat and water flows yields the variation of temperature and water content of a material. It is admitted that water vapor enters node $\mathrm{i}$ with temperature $T_{i-1}$ and condenses at temperature $T_{i}$. Similarly it evaporates and leaves at temperature $T_{i}$. Liquid water is admitted to enter with temperature $T_{i-1}$ and to leave at temperature $T_{i}$. To describe this process the evaporation and liquid enthalpies $H_{v}$ and $H_{l}$ are introduced to the heat balance equation. The thermal inertia is the sum of the dry thermal inertia $\rho \cdot c$ (density, specific heat capacity) and the thermal inertia of water contained in the node $w_{i} \cdot c_{w}\left(c_{w}\right.$ : specific heat capacity of water).

$d_{i} \cdot\left[\left(\rho \cdot c+w_{i} \cdot c_{w}\right) \cdot \dot{T}_{i}+H_{l, i} \cdot \dot{w}_{i}\right]=$

$\dot{q}_{i-1}-\dot{q}_{i}$

$+\dot{m}_{v, i-1} \cdot\left(H_{v, i-1}-H_{l, i}\right)$

$-\dot{m}_{v, i} \cdot\left(H_{v, i}-H_{l, i}\right)$

$+\dot{m}_{l, i-1} \cdot\left(H_{l, i-1}-H_{l, i}\right)$

The variation of the water content $w_{i}$ in node $\mathrm{i}$ is obtained from the sum of entering and leaving mass flows.

$$
\begin{aligned}
& d_{i} \cdot \dot{w}_{i}= \\
& \dot{m}_{v, i-1}-\dot{m}_{v, i}+\dot{m}_{l, i-1}-\dot{m}_{l, i}
\end{aligned}
$$

\subsection{Surfaces}

A surface exchanges heat and moisture between air and the adjacent material layer. The heat exchange takes into account convection due to the temperature difference between wall and air $\left(h_{c}\right.$ : convective heat transfer coefficient) and the enthalpy flow of the exchanged water vapor (equation (8)).

The moisture flow is determined by the convective moisture transfer coefficient $\beta_{\mathrm{c}}$ and the water vapor pressure difference (equation (9))

$\dot{q}_{c v}=h_{c} \cdot\left(T_{\text {air }}-T_{\text {wall }}\right)$

$+\dot{m}_{v} \cdot\left(H_{v, \text { air }}-H_{v, \text { wall }}\right)$

$\dot{m}_{v}=\beta_{c} \cdot\left(p_{\text {water,air }}-p_{\text {water,wall }}\right)$

Inner surfaces exchange heat by radiation. An approximated form factor of a surface is obtained by equation (10), where $\varepsilon$ is the long-wave emissivity of the surface and $A$ its area. The radiation between surfaces is estimated in a radiation node model that distributes radiation between surfaces. Radiative 
sources are distributed on all surfaces contained in the domain (equation (11))

$f_{i}=\frac{\epsilon_{i} \cdot A_{i}}{\sum_{\text {domain }} \epsilon_{j} \cdot A_{j}}$

$\dot{q}_{\text {rad }, l w, i}=\sigma \cdot \varepsilon_{i} \cdot \sum_{j \in \text { domain }} f_{j} \cdot\left(T_{i}^{4}-T_{j}^{4}\right)$

$+\sum_{\text {sources }} f_{i} \cdot \dot{q}_{\text {rad,source }}$

For outer surfaces, the long wave terrestrial radiation, the long wave atmospheric radiation and the short wave solar radiation are taken into account.

\section{Application example}

An insulated car cabin (Figure 8) is considered as application example. Four passengers are supposed to travel one hour in the morning and one hour in the evening from Monday to Friday in the region of Holzkirchen, Germany, during January 2011. During weekend the car is not used. Passengers emit heat and moisture according to sedentary work.

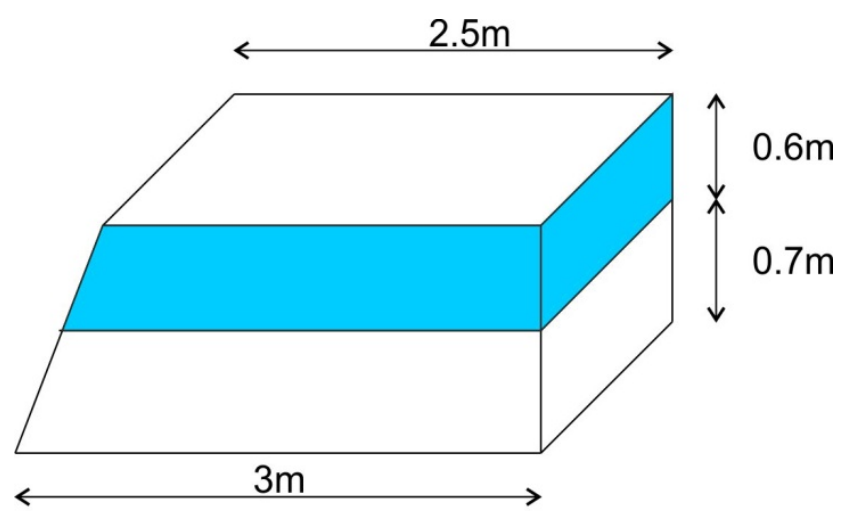

\section{$\square$ Wall}

\section{Window}

Figure 8: Vehicle geometry

Cabin enclosures are assumed to consist of three layers: $1 \mathrm{~mm}$ aluminium, $10 \mathrm{~mm}$ mineral wool and $1.2 \mathrm{~mm}$ cloth ( $50 \%$ wool, $50 \%$ viscose). Fenestration is assumed to be a one-pane window with a transmittance of 0.84 for solar radiation. The vehicle is oriented southwards. Leakages are supposed to lead to one air change per hour $(\mathrm{ACH})$ in the cabin. A ventilation system is running during occupation of the vehicle. This system is assumed to deliver $50 \mathrm{ACH}$. The supply temperature is controlled to result in a cabin air temperature of $22{ }^{\circ} \mathrm{C}$. Outdoor conditions are taken from the weather station of Fraunhofer IBP in Holzkirchen, Germany.

Simulation results show a considerable accumulation of water in the insulation (Figure 9). Besides the increased risk of mold growth this leads to increased heat conductivity degrading the performance of the insulation (Figure 10).

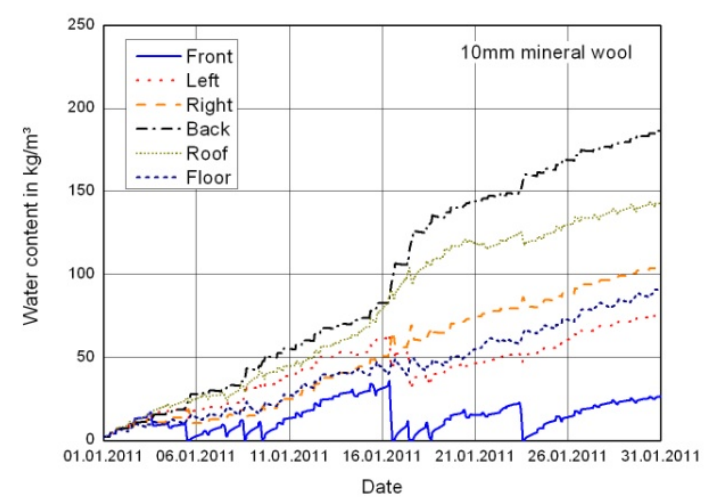

Figure 9: Accumulation of water in the vehicle insulation (10mm)

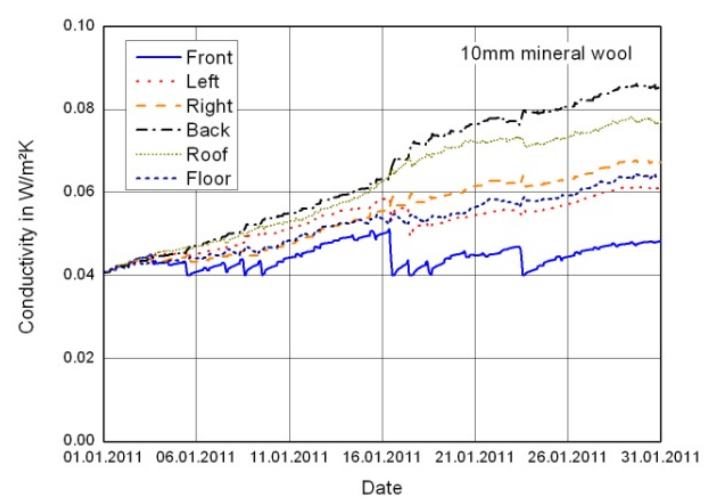

Figure 10: Thermal conductivity of the vehicle insulation (10mm)

To improve the situation the thickness of the insulation can be increased. This leads to higher surface temperature on the cabin side of the insulation resulting in a lower gradient of water vapor pressure thus leading to a lower moisture flow into the insulation. Figure 11 and Figure 12 show moisture content and thermal conductivity when increasing the thickness of mineral wool to $30 \mathrm{~mm}$. The gain of this measure is twofold. A thicker insulation presents a higher resistance to heat. Furthermore, the conductivity of the thicker insulation is lower as less water accumulates. 


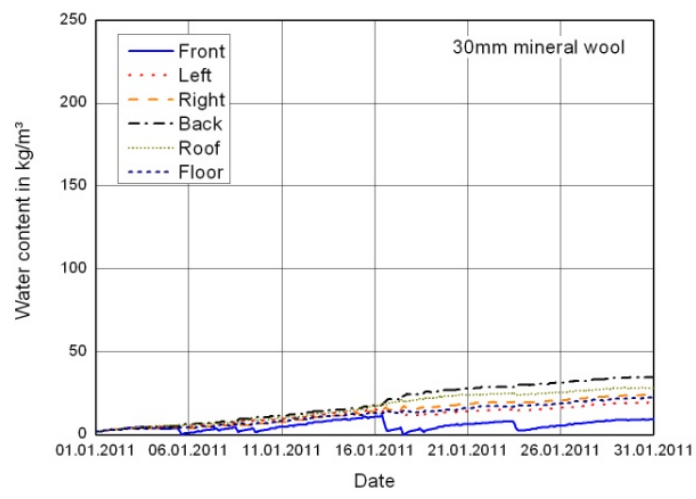

Figure 11 Accumulation of water in the vehicle insulation (30mm)

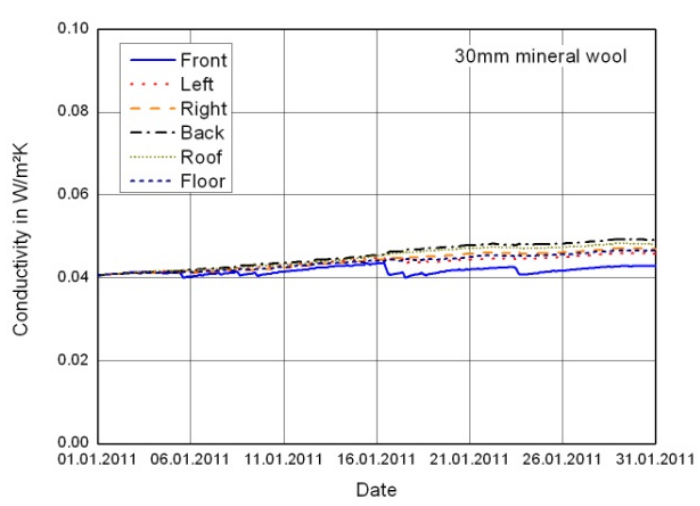

Figure 12: Thermal conductivity of the vehicle insulation (30mm)

\section{Ongoing developments}

The next step in the development of the Indoor Climate Library is to implement more functionalities than currently available. More detailed radiation models allowing the use of user-defined form factors and templates of predefined form factors for simple generic geometries will be introduced. A database of convective heat and moisture transfer coefficient correlations will be inserted. Interfaces will allow the use of the Air Conditioning Library [10] to model the air supply from HVAC systems. Templates for generic building and vehicle setups will be added. Further application examples will give an overview of the possibilities of the Indoor Climate Library.

\section{Conclusion}

The Indoor Climate Library allows computing heat and moisture transfer in constructions. A vehicle ap- plication example shows that the applied usage profile the selected wall layer construction leads to accumulation of moisture in the insulation. The Indoor Climate Library allows quick estimation of remedies to this problem. Increasing the thickness of the insulation reduced water accumulation noticeably.

\section{References}

[1] Nouidui, T.: Entwicklung einer objektorientierten Modellbibliothek zur Ermittlung und Optimierung des hygrothermischen und hygienischen Komforts in Räumen, Thesis, Universität Stuttgart, 2008

[2] LBNL Website, consulted 07. March 2012, http://simulationresearch.lbl.gov/modelica

[3] Wetter, M.: Modelica library for building heating, ventilation and air-conditioning systems, 7th International Modelica Conference, Como, Italy, 20.-22. September 2009

[4] Wetter, M., Zuo, W., Nouidui, T.: Modeling of heat transfer in rooms in the Modelica "Buildings" Library, Building Simulation, Sydney, Australia, 14.-16. November 2011

[5] Wetter, M., Zuo, W., Nouidui, T.: Recent developments in the Modelica "Buildings" Library for Building Energy and Control Systems, 8th International Modelica Conference, Dresden, Germany, 20.-22. March 2011

[6] Sedlbauer, K.: Vorhersage von Schimmelpilzbildung auf und in Bauteilen, Thesis, Universität Stuttgart, 2001

[7] Fraunhofer IRB: MASEA - Denkmalpflege, consulted on 07. May 2012, http://www.irb.fraunhofer.de/denkmalpflege/an gebote partner/masea/

[8] Künzel, H.: Verfahren zur ein- und zweidimensionalen Berechnung des gekoppelten Wärmeund Feuchtetransports in Bauteilen mit einfachen Kennwerten, Thesis, Universität Stuttgart, 1994

[9] Fraunhofer IBP Wufi Website, consulted 07. March 2012, www.wufi.de

[10] Modelon AB: Flyer of Dymola Air Conditioning Library, 2012, http://www.modelon.com/fileadmin/user uploa d/Products/Modelon/ACL/Modelon_ACL_flyer .pdf 
